\title{
Assessment of Gender Differences in General Health Status among Different Levels of Managers of Multinational Companies - A Comparative Study
}

\author{
C. Bindu Ashwini
}

\begin{abstract}
The present study attempts to assess the General health status of employees of multinational companies (MNC)in and around Bangalore . A total of 240 respondents, with equal number of male and female respondents belonging to top and medium managerial levels, completed the General Health Questionnaire developed by Goldberg (1972) in order to provide the information about the current mental status of the employee in the organization and thus enabling the examiner to identify the possible psychological disturbance in that employee. Results revealed that in four factors of General Health Status significant differences existed between male and female employees of MNC employees. General health status contributes maximum stress for the top level managerial employees than medium level employees. In general health status male employees show high score for the areas social dysfunction, severe depression. Female employees show high score for the areas somatic symptoms, anxiety and insomnia. General health status contributes maximum stress for the top level managerial employees than medium level employees. Male employees showed significantly higher somatic symptoms and social dysfunctions than females' employees. Top managerial level male employees had higher social dysfunction than female employees. Social Dysfunction is highly significant for MNC employees. The general health status of both top level and medium managerial levels contributes maximum stress. Significant interaction effects were observed between gender and managerial levels too. Lastly, remedial measures to improve the mental health and get away with job stress are discussed.
\end{abstract}

Index Terms-General health status, psychological morbidity; male and female employees, multinational companies, top level and medium level managers.

\section{INTRODUCTION}

When all the psychological processes of the individual like attention, perception, remembering, thinking, reasoning and creativity etc. function in a normal way and the person is able to adjust and cope suitably with his environment, he meets the various demands of life on his own quite successfully he is said to have sound mental health. Such a person experiences reasonably less tension, anxiety, worry, conflict and stress is able to resolve his emotional problems in a reasonable and balanced way and by and large solves the various problems of life successfully. Fisher [1] (1984) has proposed that mental activity in the perception and response to stress forms the essential basis of worry and preoccupation

Manuscript received September 19, 2013; revised November 26, 2013.

C. Bindu Ashwini is with the R. V. College of Engineering (e-mail: author@ boulder.nist.gov). and is likely to be concerned with the assessment and establishment of control. The perception of personal control is not only likely determinant of psychological response, but as been shown to determine hormone pattern. Studies have suggested that control over the work place dictates the patterns of non- adrenaline and adrenaline balance and may determine the degree of experienced anxiety Working conditions form an important source of potential stress and may have a pervasive influence on mental state and physical health in the long term.

Traditional Indian medicine, Ayurveda, which is more than 2000 years old, stated that certain types of people based on somatotype and personality, had a greater proneness to certain diseases (Solomon [2], 1984). Research indicates that routine hassles at work may have significant harmful effects on mental and physical health. Research reveals that stress often plays a role in the onset of full-fledged psychological problems including depression, anxiety, etc

\section{Methodology}

TABLE I: DISTRIBUTION OF THE SAMPLE ACCORDING TO GROUPS AND MANAGERIAL LEVELS

\begin{tabular}{|l|c|c|c|}
\hline \multirow{2}{*}{ Gender } & \multicolumn{2}{|c|}{ MNC'S } & \multirow{2}{*}{ Total } \\
\cline { 2 - 3 } & Top level & $\begin{array}{c}\text { Medium } \\
\text { level }\end{array}$ & \\
\hline Male & 60 & 60 & 120 \\
\hline Female & 60 & 60 & 120 \\
\hline Total & 120 & 120 & 240 \\
\hline
\end{tabular}

\section{A. Tools}

Following tools were employed in the present study:

1) Personal data sheet.

2) General health questionnaire by Goldberg and Hiller (1972).

Personal data sheet: The socio-demographic data for the present research will be elicited using this personal data sheet. The researcher prepares this schedule himself. This is a detailed schedule, which consists of provision to collect data on age, sex, education, occupation, income, marital status and religion of the patient and the head of the family. In addition, data will be elicited with regard to the family in terms of type, size, and family members. Etc.

\section{B. General Health Questionnaire}

This was developed by Goldberg (1972) in order to screen and identify potentially mentally ill patients in general practice. It is a self-administered scale referring to recent symptoms appeared within the past few weeks. The 
questionnaire provides information about the current mental status of the subject and thus enabling the examiner to identify the possible psychiatric disturbance in that subject.

However, it does not provide any information about the personality of the respondent nor it has any predictive value. The presence and severity of psychological symptoms can be assessed through the GHQ. Scaled GHQ is a 28 item questionnaire, which is a modified version of GHQ of Goldberg and Hiller(1972)and has been used as a first stage screening method for the general population. The scaled version of the GHQ is intended for use in studies in which an investigator requires more information than is provided by a single severity score. GHQ consists of four sub-tests they are:

1) Somatic symptoms.

2) Anxiety and insomnia.

3) Social dysfunction.

4) Severe depression.

The questionnaire is usually completed in 10 to 15 minutes of time.

Several authors (Goldberg, 1972) have established the GHQ's reliability and validity. However it is less useful when respondents are defensive or if they are suffering from schizophrenia, dementia and other psychotic diseases. Each item in this scale consists of a set of questions asking whether the respondent has recently (over past few weeks) experienced a particular symptom or a particular behavior on a 4 point scale rating by underlining the options Better than usual ,same as usual,worse than usual ,much more than usual. Questionnaire starts with items having somatic basis, as it is presented. In this scale, by avoiding the bimodal response scale, the errors due to overall agreement is reduced and error of central tendency is also eliminated. The method of scoring GHQ was developed on the basis of the results of principal component analysis (Goldberg and Hiller, 1979). Since 1979, GHQ has gained popularity. The optimum threshold for case detection as a severity test was found to be a score of 5-6 and above (Lykours, etal, 1996).

\section{SCORING}

The score of zero is given to the first two answers and a score of one is given to the remaining two answers

1) Better than usual - a score of zero

2) Same as usual - a score of zero

3) Worse than usual - a score of one

4) Much more than usual - a score of one

\section{A. Categories}

- A-Somatic Symptoms

- B-Anxiety Insomnia

- C-Social Dysfunctions

- D-Severe Depression

\section{B. Details of the Sample}

A sample of 240 employees was drawn from various types of organization. The sample of 60 male top level employees and 60 male medium level employees, and 60 female top level and medium level employees of MNC's employees was taken.

Primarily the organization where the data was to be collected was identified and the contact made through concerned persons at the personnel department, after explaining the purpose of the research study, the permission was obtained. With the assistance of the personnel department the high medium level employees were identified. With these perspectives the employees were met personally or contacts were made through phone and appointments were booked. Prior to the administration of the questionnaire the respondents were told that they had to at least spend their 1 hour and co- operate.

\section{Statistics}

MANOVA has been employed to test the significance of the difference between means of subscales of GHQ among the top and medium managerial level employees of multinational companies SPSS for Windows (version14.0 Evaluation version) has been employed in the statistical analysis

\section{RESULTS}

Individual effects: Only in 2 sub scales significant differences existed between the top level and medium level MNC employees. In the factors like Somatic symptoms, anxiety insomnia no significant differences were found between the two employee groups. Between top and middle managerial levels no significant differences were obtained for all the factors as the obtained $F$ values failed to reach the significant level criterion. However, when gender was considered irrespective of employee group and managerial level, significant difference was observed only in somatic symptoms and social dysfunctions where males had higher symptoms than female employees.

Interaction effects: When groups and levels interactions were verified none of the interaction effects were found to be significant. However when group and level interactions were considered only in somatic symptoms, social dysfunction, and severe depression significant interaction was observed. When managerial level and gender interactions were verified at least in two of the factors significant interaction effects were observed-social dysfunction and severe depression, where in anxiety insomnia, severe depression and social dysfunction, in top level females show higher symptoms and in medium level males had higher symptoms. In psychological morbidity, males belonging to top level had higher levels of symptoms and females of medium levels had higher symptoms for severe depression. On the whole the top level managerial MNC employees show more in psychological morbidity.

TABLE II: MEAN SOMATIC SyMPTOMS SCORES OF MALE AND FEMALE EMPLOYEES WITH DIFFERENT DESIGNATIONS WORKING IN MULTINATIONAL COMPANIES (MNC)

\begin{tabular}{|l|l|l|l|}
\hline \multirow{2}{*}{ Designation } & \multirow{2}{*}{ Gender } & GHQ A Somatic Symptoms \\
\cline { 3 - 4 } & & Mean & S.D \\
\hline \multirow{3}{*}{ Top Level } & Male & 2.32 & 1.86 \\
\cline { 2 - 4 } & Female & 3.22 & 2.18 \\
\cline { 2 - 4 } & Total & 2.70 & 2.04 \\
\hline Medium Level & Male & 1.85 & 1.90 \\
\cline { 2 - 4 } & Female & 1.87 & 1.71 \\
\cline { 2 - 4 } & Total & 1.86 & 1.79 \\
\hline
\end{tabular}


Individual Effects: In the area Somatic symptoms significance differences exists between top level and medium level MNC employees $(F=1.350 ; P=0.0246)$. Between top and middle managerial levels significant differences were obtained for the factors somatic symptoms as the obtained $\mathrm{F}$ values reach the significant level criterion $(F=5.754$; $P=0.017)$. However, when gender was considered irrespective of employee group and managerial level, no significance difference is observed where females had higher score than male employees. The top managerial level of MNC shows higher scores.

TABLE III: RESULTS OF 3-WAY ANOVA FOR MEAN SOMATIC SYMPTOMS SCORES OF MALE AND FEMALE EMPLOYEES WITH DIFFERENT DESIGNATIONS WORKING IN MULTINATIONAL COMPANIES (MNC)

\begin{tabular}{|c|c|c|c|c|c|}
\hline Source of variation & $\begin{array}{c}\text { Sum of } \\
\text { Squares }\end{array}$ & df & $\begin{array}{c}\text { Mean } \\
\text { Square }\end{array}$ & $\boldsymbol{F}$ value & $\boldsymbol{P}$ value \\
\hline Groups & 5.423 & 1 & 5.423 & 1.350 & 0.246 \\
\hline Gender & 6.974 & 1 & 6.974 & 1.736 & 0.188 \\
\hline Designation & 23.109 & 1 & 23.109 & 5.754 & 0.017 \\
\hline Group $\times$ Gender & 4.991 & 1 & 4.991 & 1.243 & 0.266 \\
\hline Group $\times$ Designation & 23.584 & 1 & 23.584 & 5.872 & 0.016 \\
\hline Gender $\times$ Designation & 1.407 & 1 & 1.407 & .350 & 0.554 \\
\hline Group $\times$ Gender $\times$ Designation & 34.008 & 1 & 34.008 & 8.468 & 0.004 \\
\hline Error & 1895.615 & 472 & 4.016 & & \\
\hline Total & 4400.000 & 480 & & & \\
\hline Corrected Total & 1996.925 & 479 & & & \\
\hline
\end{tabular}

Interaction effects: When groups and levels interactions were verified interaction effects were found to be significant $(F=5.872 ; P=0.016)$. However when group and gender interactions were considered no significant interaction was observed. The group and level interactions were considered no significant interaction is observed $(F=5.872 ; P=0.016)$. The top level managerial female employees had higher score. When managerial level and gender interactions were verified no significant interaction effects were observed. The medium level female employees of MNC had higher scores. When groups, levels and gender interactions were verified interaction effects were found to be significant $(F=8.468$; $P=0.004)$.

TABLE IV: MEAN ANXIETY AND INSOMNIA SCORES OF MALE AND FEMALE EMPLOYEES WITH DIFFERENT DESIGNATIONS WORKING IN MULTINATIONAL COMPANIES (MNC)

\begin{tabular}{|l|l|l|l|}
\hline \multirow{2}{*}{ Designation } & \multirow{2}{*}{ Gender } & GHQ B Anxiety and Insomnia \\
\cline { 3 - 4 } & & Mean & S.D \\
\hline \multirow{3}{*}{ Top Level } & Male & 2.21 & 1.99 \\
\cline { 2 - 4 } & Female & 3.12 & 2.08 \\
\cline { 2 - 4 } & Total & 2.59 & 2.07 \\
\hline Medium Level & Male & 2.17 & 2.10 \\
\cline { 2 - 4 } & Female & 1.85 & 1.63 \\
\cline { 2 - 4 } & Total & 2.00 & 1.86 \\
\hline
\end{tabular}

Individual Effects: Significance differences exists between top level and medium managerial level of MNC employees $(F=24.507 ; P=0.000)$ in the area Anxiety Insomnia. Between top and middle managerial levels significant differences were obtained for the factor anxiety and insomnia as the obtained $\mathrm{F}$ values reach the significant level criterion $(F=5.754$; $P=0.017)$. However, when gender was considered irrespective of employee group and managerial level, no significance difference is observed where females had higher score than male employees. The top managerial level had higher scores than the medium level.
TABLE V: RESULTS OF 3-WAY ANOVA FOR MEAN ANXIETY AND INSOMNIA SCORES OF MALE AND FEMALE EMPLOYEES WITH DIFFERENT DESIGNATIONS WORKING IN MULTINATIONAL COMPANIES (MNC)

\begin{tabular}{|c|c|c|c|c|c|}
\hline Source of variation & $\begin{array}{c}\text { Sum of } \\
\text { Squares }\end{array}$ & df & $\begin{array}{c}\text { Mean } \\
\text { Square }\end{array}$ & $\boldsymbol{F}$ value & $\boldsymbol{P}$ value \\
\hline Groups & 79.540 & 1 & 79.540 & 24.507 & 0.000 \\
\hline Gender & 4.697 & 1 & 4.697 & 1.447 & 0.230 \\
\hline Designation & 4.017 & 1 & 4.017 & 1.238 & 0.267 \\
\hline Group $\times$ Gender & .940 & 1 & .940 & .290 & 0.591 \\
\hline Group $\times$ Designation & 24.233 & 1 & 24.233 & 7.466 & 0.007 \\
\hline Gender $\times$ Designation & 6.534 & 1 & 6.534 & 2.013 & 0.157 \\
\hline Group $\times$ Gender $\times$ Designation & 15.390 & 1 & 15.390 & 4.742 & 0.030 \\
\hline Error & 1531.946 & 472 & 3.246 & & \\
\hline Total & 3476.000 & 480 & & & \\
\hline Corrected Total & 1666.367 & 479 & & & \\
\hline
\end{tabular}

Interaction effects: When groups and levels interactions were verified interaction effects were found to be significant $(F=5.872 ; P=0.016)$. However when group and gender interactions were considered no significant interaction was observed. The group and level interactions were considered no significant interaction is observed $(F=7.466 ; P=0.007)$. The top level male employees of MNC had higher scores. Further, the mean values clearly revealed that in MNC top level female employees had higher score. When managerial level and gender interactions were verified no significant interaction effects were observed $(F=2.013 ; P=0.157)$. The medium level female employees of $\mathrm{MNC}$ had higher scores. When groups, levels and gender interactions were verified interaction effects were found to be significant $(F=8.468$; $P=0.004)$.

TABLE VI: MEAN SOCIAL DYSFUnCTION SCORES OF MALE AND FEMALE EMPLOYEES WITH DIFFERENT DESIGNATIONS WORKING IN MULTINATIONAL COMPANIES (MNC)

\begin{tabular}{|l|l|l|l|}
\hline Designation & Gender & \multicolumn{2}{|l|}{ GHQ C Social Dysfunction } \\
\cline { 3 - 4 } & & Mean & S.D \\
\hline \multirow{3}{*}{ Top Level } & Male & 1.95 & 1.98 \\
\cline { 2 - 4 } & Female & 2.52 & 2.01 \\
\cline { 2 - 4 } & Total & 2.19 & 2.01 \\
\hline Medium Level & Male & 1.81 & 1.87 \\
\cline { 2 - 4 } & Female & 1.29 & 1.63 \\
\cline { 2 - 4 } & Total & 1.53 & 1.76 \\
\hline
\end{tabular}

TABLE VII: RESULTS OF 3-WAY ANOVA FOR MEAN SOCIAL DYSFUNCTION SCORES OF MALE AND FEMALE EMPLOYEES WITH DIFFERENT DESIGNATIONS WORKING IN MULTINATIONAL COMPANIES (MNC)

\begin{tabular}{|c|c|c|c|c|c|}
\hline Source of variation & $\begin{array}{c}\text { Sum of } \\
\text { Squares }\end{array}$ & df & $\begin{array}{c}\text { Mean } \\
\text { Square }\end{array}$ & $\begin{array}{c}\boldsymbol{F} \\
\text { value }\end{array}$ & $\begin{array}{c}\boldsymbol{P} \\
\text { value }\end{array}$ \\
\hline Groups & 52.920 & 1 & 52.920 & 18.310 & 0.000 \\
\hline Gender & .959 & 1 & .959 & 0.332 & 0.565 \\
\hline Designation & 6.439 & 1 & 6.439 & 2.228 & 0.136 \\
\hline Group $\times$ Gender & 1.543 & 1 & 1.543 & 0.534 & 0.465 \\
\hline Group $\times$ Designation & 22.126 & 1 & 22.126 & 7.655 & 0.006 \\
\hline Gender $\times$ Designation & 4.164 & 1 & 4.164 & 1.441 & 0.231 \\
\hline Group $\times$ Gender $\times$ Designation & 13.710 & 1 & 13.710 & 4.743 & 0.030 \\
\hline Error & 1364.210 & 472 & 2.890 & & \\
\hline Total & 2656.000 & 480 & & & \\
\hline Corrected Total & 1465.300 & 479 & & & \\
\hline
\end{tabular}

Individual Effects: In the area Social dysfunction significance differences exists between top level and medium managerial level of MNC employees ( $F=18.310 ; P=0.000)$. Between top and middle managerial levels significant differences were obtained for the factor social dysfunction as the obtained $F$ values failed to reach the significant level criterion. However, when gender was considered irrespective of employee group and managerial level, no significance 
difference is observed where females had higher score than male employees. The top managerial level of MNC had higher scores.

Interaction effects: When groups and levels interactions were verified interaction effects were found to be significant $(F=7.655 ; P=0.006)$. However when group and gender interactions were considered no significant interaction was observed $(F=0.534 ; \quad P=0.465)$. The group and level interactions were considered no significant interaction is observed. The top level female employees of MNC had higher scores. Further, the mean values clearly revealed that in MNC top level female employees had higher score. When managerial level and gender interactions were verified no significant interaction effects were observed $(F=1.441$; $P=0.231$ ). The medium level male employees of MNC had higher scores. When groups, levels and gender interactions were verified interaction effects were found to be significant $(F=4.743 ; P=0.030)$.

TABLE VIII: MEAN SEVERE DEPRESSION SCORES OF MALE AND FeMALE EMPLOYEES WITH DIFFERENT DESIGNATIONS WORKING IN MULTINATIONAL COMPANIES (MNC)

\begin{tabular}{|l|l|l|l|}
\hline \multirow{2}{*}{ Designation } & \multirow{2}{*}{ Gender } & \multicolumn{2}{|l|}{ GHQ D Severe Depression } \\
\cline { 3 - 4 } & & Mean & S.D \\
\hline \multirow{3}{*}{ Top Level } & Male & 2.42 & 2.27 \\
\cline { 2 - 4 } & Female & 2.45 & 2.32 \\
\cline { 2 - 4 } & Total & 2.43 & 2.28 \\
\hline \multirow{3}{*}{ Medium Level } & Male & 1.60 & 1.72 \\
\cline { 2 - 4 } & Female & 1.44 & 2.03 \\
\cline { 2 - 4 } & Total & 1.51 & 1.88 \\
\hline
\end{tabular}

TABLE IX: RESULTS OF 3-WAY ANOVA FOR MEAN SEVERE DEPRESSION SCORES OF MALE AND FEMALE EMPLOYEES WITH DIFFERENT

DESIGNATIONS WORKING IN MULTINATIONAL COMPANIES (MNC)

\begin{tabular}{|c|c|c|c|c|c|}
\hline Source of variation & $\begin{array}{c}\text { Sum of } \\
\text { Squares }\end{array}$ & df & $\begin{array}{c}\text { Mean } \\
\text { Square }\end{array}$ & $\boldsymbol{F}$ value & $\boldsymbol{P}$ value \\
\hline Groups & 124.990 & 1 & 124.990 & 40.485 & 0.000 \\
\hline Gender & 0.421 & 1 & 0.421 & 0.136 & 0.712 \\
\hline Designation & 23.255 & 1 & 23.255 & 7.532 & 0.006 \\
\hline Group $\times$ Gender & 0.005 & 1 & 0.005 & 0.002 & 0.967 \\
\hline Group $\times$ Designation & 24.255 & 1 & 24.255 & 7.856 & 0.005 \\
\hline Gender $\times$ Designation & 0.114 & 1 & 0.114 & 0.037 & 0.848 \\
\hline Group $\times$ Gender $\times$ Designation & 1.702 & 1 & 1.702 & 0.551 & 0.458 \\
\hline Error & 1457.223 & 472 & 3.087 & & \\
\hline Total & 2717.000 & 480 & & & \\
\hline Corrected Total & 1657.898 & 479 & & & \\
\hline
\end{tabular}

Individual Effects: In the area Severe Depression significance differences exists. Between top and middle managerial levels significant differences were obtained for the factors severe depression as the obtained $\mathrm{F}$ values reach the significant level criterion $(F=7.532 ; P=0.006)$. However, when gender was considered irrespective of employee group and managerial level, no significance difference is observed where males had higher score than female employees. The medium managerial level had higher scores than the top level.

Interaction effects: When groups and levels interactions were verified interaction effects were found to be significant $(F=7.865 ; P=0.005)$. However when group and gender interactions were considered no significant interaction was observed $(F=0.002 ; \quad P=0.967)$. The group and level interactions were considered no significant interaction is observed. Further, the mean values clearly revealed that in MNC top level female employees had higher score. When managerial level and gender interactions were verified no significant interaction effects were observed $(F=0.037$; $P=0.848$ ). The medium level male employees of MNC had higher scores. When groups, levels and gender interactions were verified no interaction effects were found to be significant $(F=0.551 ; P=0.458)$.

TABLE X: MEAN GHQ Total SCORES of MALE AND FEMALE EMPLOYEES WITH DIFFERENT DESIGNATIONS WORKING MULTINATIONAL COMPANIES

\begin{tabular}{|l|l|c|c|}
\hline \multirow{2}{*}{ Designation } & \multirow{2}{*}{ Gender } & \multicolumn{2}{|c|}{ GHQ Total } \\
\cline { 3 - 4 } & & Mean & S.D \\
\hline \multirow{3}{*}{ Top Level } & Male & 8.912 & 6.690 \\
\cline { 2 - 4 } & Female & 11.31 & 7.167 \\
\cline { 2 - 4 } & Total & 9.920 & 6.971 \\
\hline Medium Level & Male & 7.425 & 5.944 \\
\cline { 2 - 4 } & Female & 6.454 & 5.166 \\
\cline { 2 - 4 } & Total & 6.902 & 5.532 \\
\hline
\end{tabular}

TABLE XI: RESULTS OF 3-WAY ANOVA FOR MEAN GHQ TOTAL SCORES OF MALE AND FEMALE EMPLOYEES WITH DIFFERENT DESIGNATIONS WORKING IN MULTINATIONAL COMPANIES (MNC)

\begin{tabular}{|c|c|c|c|c|c|}
\hline Source of variation & $\begin{array}{c}\text { Sum of } \\
\text { Squares }\end{array}$ & df & $\begin{array}{c}\text { Mean } \\
\text { Square }\end{array}$ & $\begin{array}{c}\boldsymbol{F} \\
\text { value }\end{array}$ & $\begin{array}{c}\boldsymbol{P} \\
\text { value }\end{array}$ \\
\hline Groups & 882.196 & 1 & 882.196 & 26.060 & 0.000 \\
\hline Gender & 10.111 & 1 & 10.111 & 0.299 & 0.585 \\
\hline Designation & 200.824 & 1 & 200.824 & 5.932 & 0.015 \\
\hline Group $\times$ Gender & 19.132 & 1 & 19.132 & 0.565 & 0.453 \\
\hline Group $\times$ Designation & 376.662 & 1 & 376.662 & 11.127 & 0.001 \\
\hline Gender $\times$ Designation & 9.442 & 1 & 9.442 & 0.279 & 0.598 \\
\hline Group $\times$ Gender $\times$ Designation & 217.915 & 1 & 217.915 & 6.437 & 0.011 \\
\hline Error & 15978.260 & 472 & 33.852 & & \\
\hline Total & 42905.000 & 480 & & & \\
\hline Corrected Total & 17747.448 & 479 & & & \\
\hline
\end{tabular}

Individual Effects: Significance differences exists between top and the medium level managers of the $\mathrm{MNC}(F=26.060$; $P=0.000$ ) for the GHQ TOT. Between top and middle managerial levels significant differences were obtained for the GHQ total as the obtained $F$ values reach the significant level criterion $(F=5.932 ; P=0.015)$. However, when gender was considered irrespective of employee group and managerial level, no significance difference is observed where females had higher score than male employees. The top managerial level had higher scores than medium level.

Interaction effects: When groups and levels interactions were verified interaction effects were found to be significant $(F=11.127 ; P=0.001)$. However when group and gender interactions were considered no significant interaction was observed $(F=0.565 ; \quad P=0.453)$. The group and level interactions were considered no significant interaction is observed $(F=11.127 ; P=0.001)$ The top level male employees of MNC had higher scores further, the mean values clearly revealed that in MNC top level female employees had higher score. When managerial level and gender interactions were verified no significant interaction effects were observed $(F=0.279 ; P=0.598)$. The top level male employees of MNC had higher scores. When groups, levels and gender interactions were verified interaction effects were found to be significant $(F=6.437 ; P=0.011)$.

\section{DISCUSSION}

The main findings of the present study are:

1) In general health status male employees show high score 
for the areas social dysfunction, severe depression.

2) Female employees show high score for the areas somatic symptoms, anxiety and insomnia

3) General health status contributes maximum stress for the top level managerial employees than medium level employees.

4) Male employees showed significantly higher somatic symptoms and social dysfunctions than females' employees.

5) Top managerial level male employees had higher social dysfunction than female employees

6) Social Dysfunction is highly significant for MNC employees.

7) The general health status of both top level and medium managerial levels contributes maximum stress.

There are hardly few studies on general health status especially employees working in Multinational companies. A comparison study by Srivastava, Urmila [3] (2002) Relationship of job and life stress to health outcomes among Indian managerial personnel examines the relationship between job and life stress and health outcomes of management personnel. A sample of 200 male managers completed questionnaires covering occupational stress, life stress, psychosomatic health complaints (pathogenic health habits (PHH), PHC) data on blood pressure were also collected. Job stress was significantly related to PHC and $\mathrm{PHH}$, As compared to job stress, life stress was found to be stronger than predictor of health outcomes.

Tripathy, Madanmohan [4] (2002) Burnout stress syndrome in managers studies the burnout stress syndrome among 125 managers. Subjects were administered Maslach burnout inventory and a survey questionnaire on stress as understood by them, major illness suffered, habits and strategies for reducing stress. However, only 118 respondents returned the completed questionnaire. Analyses revealed that burnout was higher among married male middle level manager who were working in the production department and those with 21-30 yrs of work experience. Managers working for over $72 \mathrm{hrs} /$ week were more susceptible to burnout. They usually suffered from hypertension, heart disease etc. and tended to bottle up their stress. Suggestions have been made for reducing stress.

Sharma [5] (2001) mental health of women in relation to job stress examines the impact of job stress on mental health. The sample comprises of 120 women in the age group of 25-35 yrs and 50 yrs above, experiencing low, moderate and high job stress. There were 40 subjects in each group. The GHQ which measures psychological distress and a mental health inventory were administered to all the subjects individually. Age and the interaction of and job stress had no significant effort on scores of the GHQ and the health inventory. The moderate job stress group was less prone to psychological depression, manifested least symptoms of neurotic disorders and had better mental health as compared to the low or high job stress group.

A study by Long [6] (1998) on women employees in Canada compared 214 clerical workers (the low control group) with 249 managers (the high control group) people with low job control were described as more distressed and less satisfied than people with high job control. The managers reported fewer hassles on the job and less depression, anxiety and health complaints.

Research by Dormann and Zapf [7] (1999) involving 543 workers in Germany found that social support offered by supervisors reduced the symptoms of depression that resulted from social stressors on the job.

Though there are no direct studies comparing the male and female employees of multinational companies, definitely we can say that the female employees of MNC face more problems as the processes are developed to fit technology, not the workers and sometimes not even the customers.

Several authors have suggested intervention strategies to improve the mental health of employees working in such conditions. They could be summarized as below-

1) Lean working practices (Sprigg and Johnson, 2006) on employee health.

2) Structural and behavioural interventions in workplace to prevent psychological morbidity (Johannes, 1994).

3) Employee assistance programme (EAP) (Johnson \& Indvik, 1997).

4) Exercise, relaxation, CBT, and net-working (Luthans, 2005).

Whatever the situation may be, whether on an individual or an organizational level, steps need to prevent or reduce the increasing job stress and psychological morbidity facing today's employees, which would be helpful for the employees in the highly uncertain world of new organizational forms.

\section{REFERENCES}

[1] V. E. Fisher, "Emotional distress and control cognitions as mediators of the impact of chronic pain on disability," British Journal of Health Psychology, vol. 3, pp. 225-236, 1984.

[2] G. F. Soloman, "Emotions, immunity and disease. An historical and philosophical perspective," in Stress, Immunity and Aging, E. L. Cooper (Ed.), New York: Morcel Delkar, Inc. Pl, 1984.

[3] U. Srivastava, "Employee's Job anxiety as a resultant of their level of job involvement," Indian Psychologist, vol. 2, no. 1, June 2002.

[4] S. Tripathy and K. Madanmohan, "Effect of life and job stress on information search behaviours of organizational members," Journal of Applied Psychology, vol. 67, pp. 60-66, 2002.

[5] K. Sharma, "Stress and strain among Indian middle managers," Indian Journal of Industrial Relations, vol. 28, no. 1, pp. 71-84, 1992.

[6] S. Long, "Performance appraisal and occupational stress," Abhigyam, vol. 18, no. 2, pp. 41- 44, 1998.

[7] K. Dormann and H. Zapf, "What is typical for call centers jobs? Job characteristics and service interactions in different Call centers," European Journal of Work and Organizational Psychology, vol. 12, no. 4, pp. 311-340, Dec. 1999.

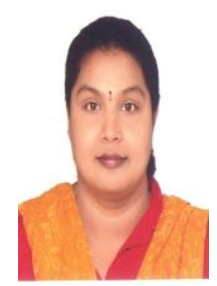

C. Bindu Ashwini is doctorate in Clinical Psychology University of Mysore. Presently working as an assistant Professor in Psychology at R. V. College of Engineering. Introduced the subject Applied Psychology for Engineers as global elective for all the branches of Engineering Courses and also designed the syllabus for the same. Visited USA, UK for paper presentation in an International Conference. Published Conference. research papers in National and International 